\title{
Information Technology and the Rise of Household Bankruptcy*
}

\author{
Borghan N. Narajabad \\ Rice University \\ Preliminary
}

December 31, 2007

\begin{abstract}
Several studies attributed the rise of household bankruptcy in the past two decades to the decline of social stigma associated with default. Stigma explanations, however, cannot account for the increase of credit availability during this period. I try to explain both of these facts as a result of a more informative credit rating technology.

I consider an adverse selection environment where borrowers are heterogeneous with respect to their cost of default. Lenders have access to a rating technology which provides an exogenous signal about borrowers' default costs. Equilibrium contracts subject each borrower to a credit limit such that the lenders' expected profit, conditional on the signal about the borrower's default cost, is zero.

As the exogenous signal becomes more informative, the credit market will provide a higher credit limit for borrowers with a high cost of default, and a lower limit for borrowers with a low cost of default. Hence a more informative signal allows those with a high cost of default to borrow more making them more likely to default, while decreasing borrowing and default by those who have a low cost of default.

Using Simulated Method of Moments, I estimate the model to match data on the averages of available credit limits and debt as well as the increase in the spread of the credit limit distribution from the Survey of Consumer Finance 1992 and 1998. The model does well in matching the targeted moments and accounts for about one third of the increase in the number of bankruptcy filings from 1992 to 1998.
\end{abstract}

Keywords: Consumer Bankruptcy, Information and Market Efficiency, Rating Agencies.

JEL Classification: G14, E44, G24, K35, E21.

\section{Introduction}

Household bankruptcy filings have been increasing in the US for the past quarter of a century. In 1984, 0.33\% of American households filed for bankruptcy. The number of filers rose to $0.93 \%$ of households in 1991 and continued to increase up to $1.41 \%$ in $2004 .{ }^{1}$ This trend can also be spotted in the number of Canadian bankruptcy filers (Livshits et al. (2005)), suggesting that the increase should not be solely attributed to legal changes in the US.

During this period, households' access to unsecured credit (mainly through credit cards) flourished. While in $1989,56 \%$ of households had access to credit cards and $29 \%$ of households carried a positive balance on their

\footnotetext{
${ }^{*}$ I am heavily indebted to Russell Cooper and Dean Corbae for their guidance and support. I wish to thank Satyajit Chatterjee, Randal Watson, Tom Wiseman, Kenneth Hendricks and Jeroen Swinkels for their helpful comments. Special thanks goes to Javad Yasari. All errors are mine.

${ }^{1}$ Just before the sweeping changes to America's bankruptcy code took effect in 2005, the number of bankruptcy filers jumped to $1.55 \%$ of American households. Unsurprisingly, the number of filers plummeted after the change went into effect. Recent data suggest the number of filers is picking up again.
} 
accounts. Fifteen years later credit card access rose to $72 \%$ and $40 \%$ of American households were carrying debt on their accounts (the latter are called revolvers in the literature). ${ }^{2}$ Moreover, the average credit card debt of revolvers increased from $\$ 1,830$ in 1989 to $\$ 3,300$ in $2004 .^{3}$ But households were not just borrowing more subject to the same credit limits. During this period the average credit card limit available for an American household more than doubled; they rose from $\$ 7,100$ in 1989 to $\$ 15,200$ in $2004 .^{4}$

The importance of credit card debt on a household's decision to file for bankruptcy has been well documented (see for example Domowitz and Sartain [11] as well as Sullivan, Warren and Westbrook [21].) Therefore, understanding the dynamics behind the expansion of credit card availability and its usage is critical for studying the rise of household bankruptcies.

Barron and Staten [6] document that expansion of the credit card industry would not be possible without rapid improvements in information technology and credit rating technologies. In 1997 credit bureaus issued some 600 million reports about credit seekers, (Padilla and Pagano [20]), and in the following decade credit scores produced by the Fair Isaac and Company, known as FICO scores, became the industry's standard tool for assessing borrowers' credit worthiness. Moreover, Edelberg [12] shows that lenders increasingly used risk-based pricing of interest rates in consumer loan markets during the mid-1990s, and Berger [5] reports that improvement in the lending capacity was due to improvements in information technology used by the banks.

This paper tries to explain the rise in the number of bankruptcy filings as a result of improvement in the credit rating technology which allows the credit market to better screen borrowers' riskiness. This might sound counter intuitive at first. When creditors separate borrowers according to their riskiness, they will tighten the credit supply for the riskier borrowers, which will make them less likely to default. However, the safer borrowers will receive a higher borrowing limit which allows them to borrow more and, in turn, can result in more default. This is because even safer borrowers, ceteris paribus, are more likely to default when their debt level is higher. The net change of the debt level and the default rate is ambiguous.

Suppose the rating technology does not work well, so the credit market lacks information on borrowers riskiness and cannot differentiate them, which I call the "pooling case". The equilibrium supply of credit will be so tight that the safer borrowers do not find it optimal to borrow much, and therefore are not paying much for the losses of the credit market from lending to the riskier borrowers. ${ }^{5}$ Now, suppose the rating technology improves, so the credit market obtains information on the riskiness of borrowers and can differentiate them, which I call the "separating case". In this case, the market will cut back the supply of credit for the riskier borrowers only slightly. Hence the default rate by these borrowers does not fall very much. On the other hand, creditors will extend the supply of credit for the now distinguished safer borrowers extensively, encouraging them to borrow and hence default more. ${ }^{6}$ I will call this the informational explanation for the rise of household bankruptcy.

The literature provides other explanations for the rise of household bankruptcies. The common explanation attributes it to the fall of "stigma" attached to bankruptcy. Gross and Souleles [14] report that ceteris paribus, a credit card holder in 1997 was almost 1 percentage point more likely to declare bankruptcy than a card holder with identical risk characteristics in 1995. Fay, Hurst and White [13] report that even after controlling for state and time fixed effects, households are more likely to file for bankruptcy if they live in districts with higher aggregate bankruptcy filings rates.

The stigma explanation, however, has counterfactual implications for credit availability and equilibrium debt levels. If borrowers become less reluctant to default on their debt, then shouldn't creditors restrain the supply of credit? and wouldn't this result in less borrowing rather than more? Athreya [1] and Livshits, MacGee and Tertilt [18] have noted that the decline in stigma alone would lead to a counterfactual decline in the ratio of unsecured debt to income. To account for the rise of consumer debt level they suggest a reduction in the transaction costs of lending. ${ }^{7}$ Livhshits et al. [18] use a combination of decline in stigma and fall in transaction costs to explain the

\footnotetext{
${ }^{2} 20 \%$ of households (69 percentage of revolvers) were carrying more than $\$ 500$ debt in 1989 . This fraction rose to $30 \%$ of households (75 percentage of revolvers) in 2004.

${ }^{3}$ All dollar amounts are in 1989 constant prices.

${ }^{4}$ A household's credit card limit is the sum of limits on all of the household's credit cards.

${ }^{5}$ For example when the riskier borrowers are much more risky than the safer ones and there are enough of them in the pool of borrowers, borrowing and default will be mostly done by the riskier ones.

${ }^{6}$ Borrowers' responsiveness to the terms of credit contracts, and specifically credit limits, are well documented by Gross and Souleles [15].

${ }^{7}$ Athreya [1] also uses the same reduction to generate the rise in filings, which leads to a significantly higher debt to income ratio than that
} 
changes in filings and the ratio of unsecured debt to income. ${ }^{8}$

But a fall in credit transaction costs cannot explain the increase in the spread of households credit card limits. While from 1992 to 1998, when bankruptcy filings rose significantly, the average American household's credit card limit increased from $\$ 7,200$ to $\$ 12,800$, the standard deviation of the cross sectional distribution of credit limits rose from $\$ 8,200$ in 1989 to $\$ 15,700$ in $2004 .{ }^{9}$. That is, the distribution of credit card limits did not just shift rightward, its spread also increased (the increase of credit limit for some households has been larger than the increase of limits for others). Gross and Souleles [14] report that creditors extended the larger lines to less risky accounts, suggesting that the spread of credit supply is mostly associated with the improvement in risk assessment.

Using a combination of the rise of stigma and fall of transaction costs to address different trends of the consumer credit industry ignores an important innovation of this industry; improvements of credit risk rating. This paper studies the implication of an improvement on the trends of the consumer credit industry. ${ }^{10}$ Specifically, I examine how the credit limit and debt distribution as well as the number of bankruptcy filings differ in a market where creditors have information about the their borrowers' types from a credit market where they do not.

Section (2) provides some facts from the data on the trend of household bankruptcies, the distributions of credit card limits and debt as well as changes in these distributions across time. Section (3) describes a model of households' demand for credit, the responsiveness of their demand to credit contracts, in particular credit limits, and the response of propensity of default to an increase of credit supply. Then the model is used to show how a more informed credit market on average supplies more credit, but the distribution of credit supply will also spread. Section (4) provides a simple quantitative example and shows the model does well in explaining the rise of credit supply, consumer debt level and the number of household bankruptcies. Section (5) concludes.

\section{Data and Motivation}

Households can file for bankruptcy under chapter 7 or 13. Under chapter 7 their unsecured debt such as credit card debt, installment loans, medical bills and damage claims are discharged, and filers lose all of their assets above an exemption level. ${ }^{11}$ Under chapter 13, filers must propose a plan to repay a portion of their debts from future income without losing their assets. Since households have the right to choose between the chapters, they are only obliged to use future earnings to repay debt to the extent they would repay under chapter 7 . Those who file under chapter 13 are allowed to file again under chapter 7, but the chapter 7 filers cannot file for another 6 years. The bankruptcy flag remains in a filer's credit history for 10 years (see Musto [19].)

Approximately $70 \%$ of those who seek bankruptcy protection file under chapter 7 and two third of those who file under chapter 13 ended up filing again under chapter $7 .{ }^{12}$ This paper, however, does not distinguish between filing under the two chapters and studies a notion of bankruptcy similar to filing under chapter 7.

Figure(1) shows the number of bankruptcy filings by American households in the past two decades. ${ }^{13}$ Except three short periods of 1992-94, 1997-2000 and 2003-04, bankruptcy filings have been increasing. From 1994 to 1997 bankruptcy filings increased by $63 \%$ during a period of robust economic expansion. ${ }^{14}$ From the Survey of Consumer Finance (SCF), I find $11 \%$ of American households had at least one time filed for bankruptcy in their lives by 2004, and from those who had filed $69.4 \%$ of them had filed in the past 10 years. That is, more than $7 \%$ of American households had a bankruptcy flag on their credit history.

${ }^{8}$ Another possible explanation for more bankruptcy filings could be the rise of "uncertainty" in households' income and emergency expenses. This explanation implies a similar counterfactual decline in credit provision. Moreover, Livshits et al. [18] find its effect on the rise of filing numbers insignificant.

${ }^{9}$ Credit limits are reported in 1989 dollars

${ }^{10}$ Chatterjee et al. [9] provide a model with dynamic updating of creditors' beliefs about borrowers' creditworthiness that they associate with credit scores. Their paper does not, however, have anything to say about trends, which is the main point of my paper.

${ }^{11}$ Exemption levels differ across states.

${ }^{12}$ See Li and Sarte [17] for an elaborated study of bankruptcy filers' choice of chapter.

${ }^{13}$ The percentage of filers for the $1984-95$ period are reported from Fay et al. [13]. The number of filings for the 1995-2005 period are from www.uscourts.gov and the number of households for this period are from www.census.gov.

${ }^{14}$ Gross and Souleles [14] study bankruptcy and delinquency of credit card holders during this period.
} 


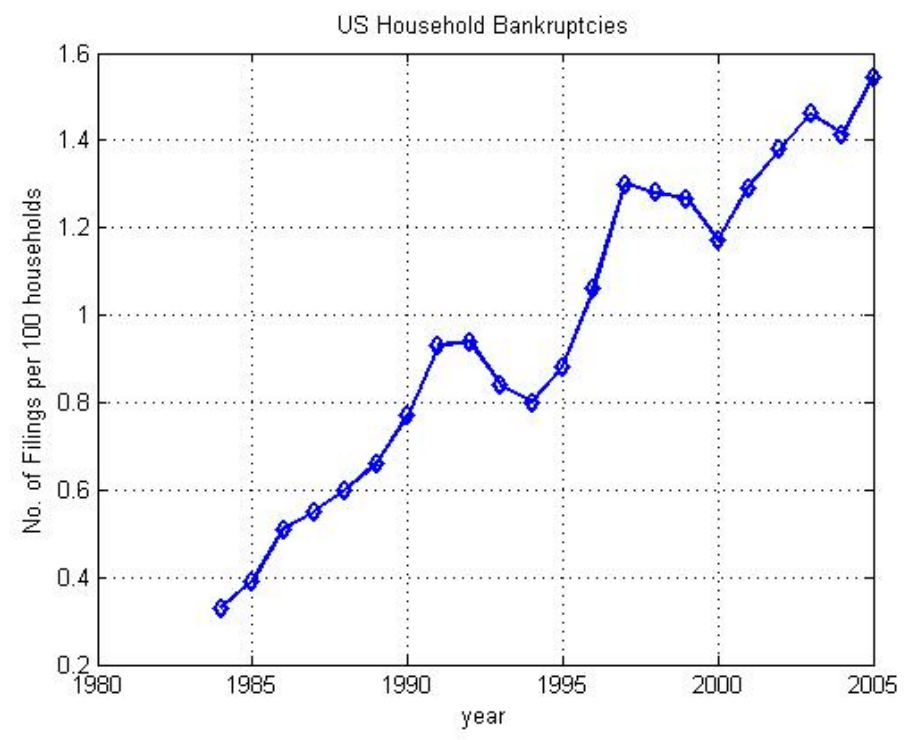

Figure 1: US Household Bankruptcies

Availability of credit cards and their usage has also been on the rise in the past two decades. Figure(2) and table (1) report the average credit limit for those who had access to credit cards and the fraction of population with credit card access from the SCF 1989-2004. The fraction of the population with positive credit card limit, which I call the extensive margin of credit supply, rose almost $17 \%$. The average credit limit for card holders, which I call the intensive margin of credit supply, more than doubled. ${ }^{15}$ Just from 1992 to 1998, the intensive margin of credit supply increased by a factor of $79 \%$.

Households also borrowed more on their credit cards. In 1989, $29 \%$ of households were revolvers (carrying positive debt on their credit cards). By 2004 the fraction of revolvers rose to $40 \%$. Revolvers' average credit card debt almost doubled in this period and went from $\$ 1,828$ in 1989 to $\$ 3,295$ in 2004. Just from 1992 to 1998, revolvers' debt increased by a factor of $59 \%$. Table (1) reports the average debt level of revolvers and households with access to credit cards. The average debt level of revolvers remains almost two times as large as the average debt level of general card holders, revolvers and non-revolvers combined.

But the increase of average credit limits and debt levels does not thoroughly summarize the changes in the distributions of these two variables. The standard deviation of the cross section of credit limits and debt levels also doubled from 1989 to 2004 . This observation is critical for the approach of the paper.

Figure (3) depicts the empirical distributions of credit limits (in 1989 dollars) in 1992 and 1998. As it can be easily noted, the distribution shifted rightward. But the shift was not caused by uniformed extension of credit supply to all card holders. The increase of credit limits for some households was larger than the increase of limits for others. To illuminate this point, figure(3) also depicts a counterfactual distribution, which is made by uniformly increasing the credit limits in 1992 to match the average credit limit of 1998. Although the credit limit distribution of 1998 and the counterfactual distribution both have the same average, the 1998 distribution is more spread. The uneven extension of credit limits is also documented by Gross and Souleles ([14]). More interestingly they report that creditors extended the larger lines to less risky accounts and provided less extension to the riskier accounts.

Credit card contracts usually consist of a credit limit and an interest rate. Table (1) reports the average and standard deviation of credit card interest rates for 1995-2004. ${ }^{16}$ From 1995 to 2001, when the Bank Prime Loan Rate (MPRIME) fluctuated between $8.00 \%-9.50 \%$, the average of credit card interest rate remained around

\footnotetext{
${ }^{15}$ Limits are given in 1989 dollars.

${ }^{16}$ SCF did not collect the credit card interest rates prior to 1995 .
} 


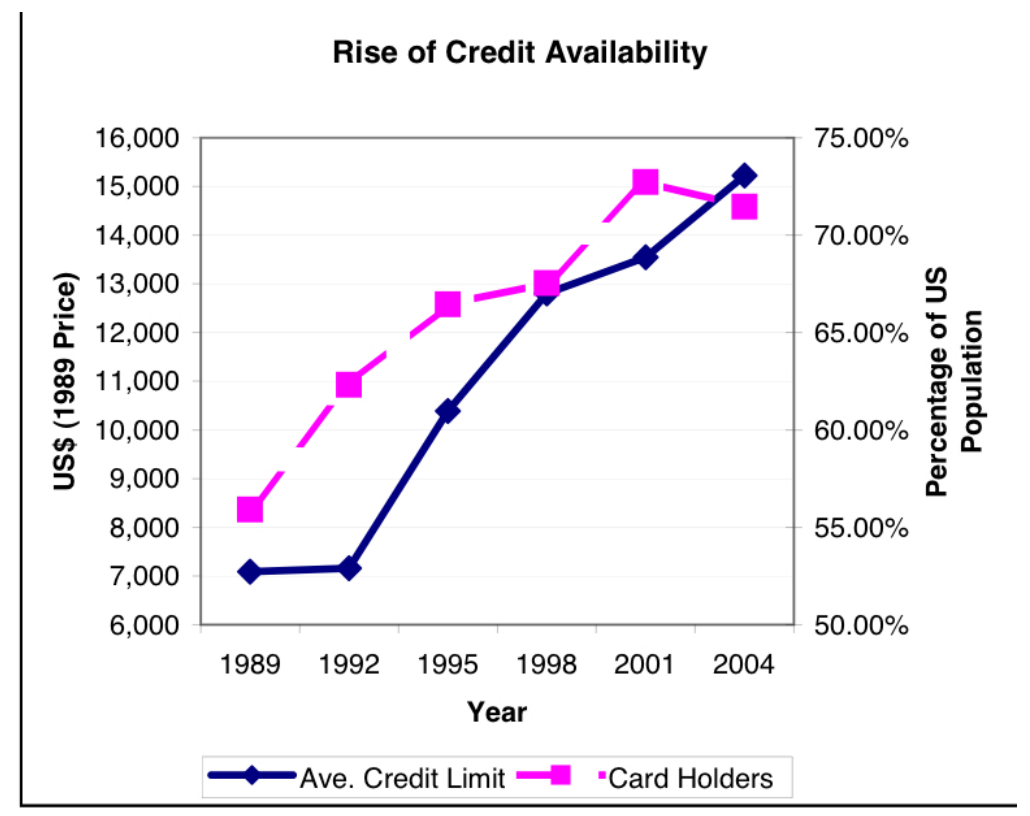

Figure 2: Rise Of Credit Availability

$14.5 \%$, and its standard deviation rose almost one percentage point from $4.29 \%$ in 1995 to $5.24 \%$ in $2001 .{ }^{17}$ The average of credit card interest rates in 2004 decreased to $11.49 \%$ while MPRIME dropped to $4.00 \%-5.00 \%$. The variation of credit card interest rates across households also rose; specifically the standard deviation increased to $6.42 \%$.

The simultaneous increase in the spreads of credit limits and interest rates indicates that creditors have started to offer more differentiated credit terms to their borrowers. Variation in credit limits, however, has increased far more than that of interest rates, especially prior to 2004. While the standard deviation of limits rose by a factor of $68 \%$ from 1995 to 2001, the standard deviation of interest rates increased by a factor of $22 \% .{ }^{18}$. This facts motivates why I focus on changes in credit limits rather than variation in interest rates.

Gross and Souleles [15] study borrowers' response to credit supply and report an average "marginal propensity to consume (MPC) out of liquidity" ( $d$ Debt/ $d$ Limit) in the range of $10-14 \%$. Their study finds that MPC is significant even for borrowers well below their limits. Average MPC of $14 \%$ implies a $\$ 790$ increase in the average credit debt for the $\$ 5,645$ increase of the average credit limit from 1992 to 1998 . The actual average increase of debt level is $\$ 671$ for this period, suggesting that the rise of debt levels can be mostly attributed to the increase of credit supply.

According to Gross and Souleles [15] the long-term elasticity of debt to the interest rate is approximately -1.3. Although the SCF does not report interest rates for 1992, the implied change of the average debt level due to the change of interest rates from 1995 to 1998 is $\$ 56$, while the actual average debt level increased $\$ 2,412$. This fact again confirms the paper's approach of focusing on the quantity side of the supply of credit, namely credit limits, rather than the price of credit, namely interest rates. ${ }^{19}$

So far, I have reported the credit card limit and debt for an average household. But how about the credit card limit and debt level of those who file for bankruptcy? The households who report bankruptcy filing in the SCF, have usually finished their legal processes and their debt levels are discharged. Moreover, after filing for bankruptcy credit cards are cancelled so no information is available from the SCF on the filers' limit. Not being a

\footnotetext{
${ }^{17}$ MPRIME is reported from the Board of Governors of the Federal Reserve System

${ }^{18}$ Stickiness of credit card interest rates have been studied by Ausubel [2] and Calem and Mester [8]

${ }^{19}$ Another challenge for studying the effect of interest rate on debt level lies in the fact that credit card prices contain other dimensions like cash back rates, flyer mileages and other point programs on which no data is available from the SCF.
} 


\begin{tabular}{lr|rrrrrr|}
\cline { 3 - 7 } & & 1989 & 1992 & 1995 & 1998 & 2001 & 2004 \\
\hline \hline Cred. Lim & Mean & 7,092 & 7,157 & 10,390 & 12,802 & 13,548 & 15,223 \\
& Debt $>0$ & 7,125 & 6,579 & 9,832 & 11,505 & 11,964 & 13,643 \\
\hline Cred. Lim & Std. & 11,296 & 8,223 & 13,151 & 17,861 & 22,055 & 20,911 \\
& Debt $>0$ & 9,624 & 7,204 & 11,233 & 15,696 & 21,645 & 18,066 \\
\hline \hline Cred. Debt & Mean & 954 & 1,025 & 1,346 & 1,696 & 1,453 & 1,851 \\
(Card Holders) & Debt $>0$ & 1,828 & 1,947 & 2,404 & 3,098 & 2,707 & 3,295 \\
\hline Cred. Debt & Std. & 2,120 & 2,303 & 3,076 & 3,979 & 4,172 & 4,246 \\
(Card Holders) & Debt $>0$ & 2,648 & 2,878 & 3,788 & 4,958 & 5,390 & 5,228 \\
\hline \hline Interest Rate & Mean & - & - & 14.51 & 14.45 & 14.36 & 11.49 \\
& Debt $>0$ & - & - & 14.14 & 14.48 & 14.20 & 11.81 \\
\hline Interest Rate & Std. & - & - & 4.29 & 4.63 & 5.24 & 6.42 \\
& Debt $>0$ & - & - & 4.46 & 5.04 & 5.62 & 6.63 \\
\hline \hline Card Holders & & $55.91 \%$ & $62.32 \%$ & $66.45 \%$ & $67.54 \%$ & $72.72 \%$ & $71.46 \%$ \\
\hline Revolvers(Debt $>0)$ & & $29.18 \%$ & $32.83 \%$ & $37.21 \%$ & $36.97 \%$ & $39.01 \%$ & $40.14 \%$ \\
\hline \hline
\end{tabular}

Table 1: Summary of US Households' Credit Cards

panel dataset, the SCF does not allow me to observe the credit card limit and debt of households just before filing for bankruptcy. ${ }^{20}$ Therefore, this paper uses the financial description of bankruptcy filers from Sullivan et al. [21].

\begin{tabular}{l|r|r} 
Credit card debt(Ratio to income) & 1991 & 1997 \\
\hline \hline Mean & $\$ 10,193(.531)$ & $\$ 12,608(.767)$ \\
s.d. & $\$ 13,751(.755)$ & $\$ 15,380(1.154)$ \\
25th percentile & $\$ 2,702(.122)$ & $\$ 3,864(.167)$ \\
median & $\$ 6,112(.310)$ & $\$ 8,262(.469)$ \\
75th percentile & $\$ 12,807(.645)$ & $\$ 14,188(.874)$
\end{tabular}

Table 2: Credit Card Debt Listed in Bankruptcy (in 1989 dollars) From Sullivan et al.

Table (2) reports the distribution of credit card debt listed in bankruptcy in 1991 and 1997 from Sullivan et al. [21]. Since the SCF data collection and report takes approximately one year, the data on filers' credit card debt corresponds to 1992 and 1998 data from the SCF. The table also reports the ratio of credit card debt to income for bankruptcy filers. The average credit card debt of filers increased by a factor of $24 \%$, and the median increased by a factor of $35 \%$, suggesting that the distribution not only shifted rightward but also spread. The increase in the ratio of credit card debt to income is even higher. The average of the ratio of credit card debt to income for filers rose $44 \%$ while the median increased by $51 \%$.

This data suggests those who were filing for bankruptcy in 1997 were defaulting on much higher levels of credit card debt. I will study how those who filed for bankruptcy could get access to more credit through higher limits and accumulate larger amounts of debt before defaulting on it.

The next section provides a framework to study the data facts I described in this section.

\section{Model}

Credit rating agencies usually use a borrower's credit history to assess her creditworthiness. Hence borrowers should potentially take into account the effect of their borrowing/payment decisions on their future terms of credit

\footnotetext{
${ }^{20}$ I tried to use the PSID, but credit limits are not reported in that dataset.
} 


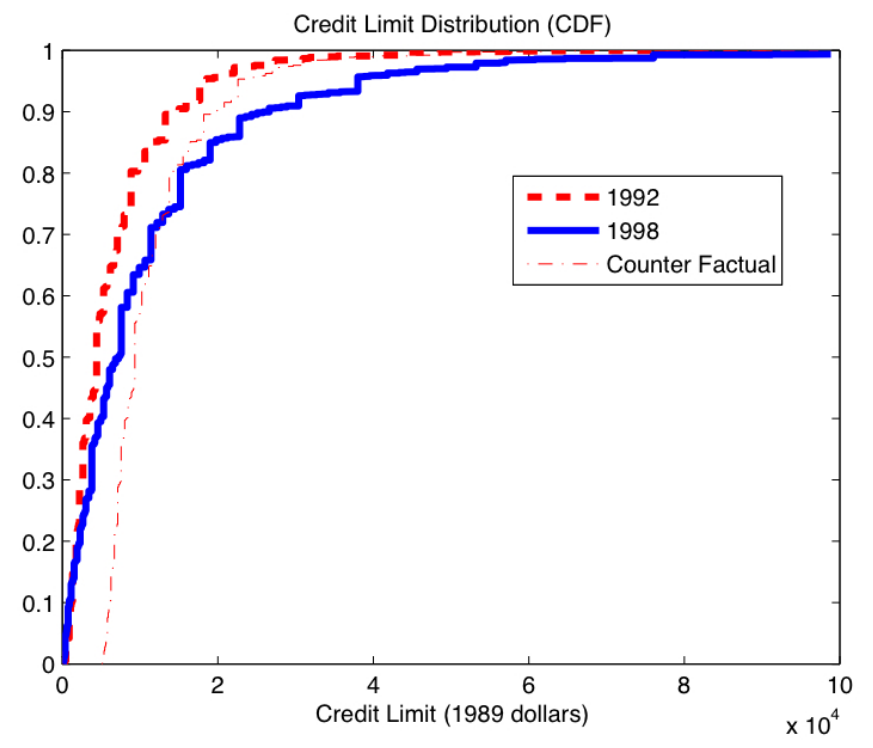

Figure 3: Distribution of Credit Limits

contracts. The natural method of modeling the credit market would be employing dynamic signaling models; these models, however, are very difficult to analyze. ${ }^{21}$ This paper takes a simple approach to model the improvement of credit risk rating. Creditors receive a public signal about borrowers' types when credit contracts are made. I use more informative signals as a proxy for the improvement of the credit rating technology. This paper abstracts away from how credit scores are developed and just focuses on the information content of signals when a household starts borrowing on its credit cards.

Musto [19] documents that creditors change their supply of credit as they lose information on the creditworthiness of borrowers due to the removal of the bankruptcy flag from their credit history ten years after the filing date. This paper tries to study what happens when creditors become more informed about the creditworthiness of borrowers due to a better credit rating technology.

It is important to notice the notion of safe and risky are relative. If a safe borrower (a borrower with a high cost of default) accumulates a large amount of debt, she may be more likely to default than a risky borrower (a borrower with a low cost of default) who has accumulated a small debt. The nature of costs associated with default are not the focus of this paper. These costs can have different pecuniary and non-pecuniary forms. An essential assumption of the paper is the heterogeneity of these costs across borrowers. That is different households with the same level of debt make different decisions on bankruptcy filings. Obviously as the level of the debt rises all households become more likely to default. This paper tries to study the implication of this heterogeneity for the supply of credit and bankruptcy filings.

As noted by Calem, Gorday and Mester [7] credit card balances show high persistence with yearly autocorrelation of 0.90. That is, households use credit cards for medium- or long-term financing rather than for short-term or unanticipated liquidity shocks. This fact is exploited by this paper in modeling households' motives for borrowing on their credit cards. Instead of using a Markovian income process with high persistence, I assume households start with an initial income, then at a random time they switch to their permanent income level, which is likely to be higher. In this framework, households are not using their credit lines to smooth their consumption whenever they receive a short-term income or liquidity shock. Instead, credit lines are used for long-term financing, an

\footnotetext{
${ }^{21}$ For an example of a model with dynamic updating of creditors' beliefs about borrowers' creditworthiness see Chatterjee et al. [9]. Extension of credit over time in their model depends on the evolution of household credit scores (or Bayesian posteriors of household type). Effectively their contracts ration through price rather than quantity limits (which is the focus of my paper). As documented in the previous section, credit limits are an important part of the contract and have experienced the greater part of variation over time.
} 
implication consistent with the data. ${ }^{22}$ Moreover, this setup allows for a very simple link between the supply of credit and households' debt level.

An average American household has about four credit cards, with usually different terms of contract (i.e. different credit limits and interest rates.) However, they tend to carry their debt on a single one which offers them the lowest interest rate. I assume each agent is only allowed to make credit contract with a single creditor she chooses. Without this assumption, the agent could be offered a continuum of contracts with incremental credit limits and increasing interest rates. In that case, the agent would start borrowing from the contract with the lowest interest rate and as her debt level increased she would use the contracts with higher interest rates. This approach is identical with offering the agent a menu of interest rates for different levels of debt. ${ }^{23}$ In order to simplify the model and focus on the credit limit dimension of credit cards, I assume each agent can only choose one contract from the contract offers she receives from creditors.

The model is general in allowing the credit contracts to vary in both credit limit as well as interest rate. For the quantitative exercise provided afterward, however, I will assume all contracts have a fixed interest rate, and they only vary in the credit limit.

In the following subsections, first I describe the environment. Then the household's problem will be studied. The creditor's problem and existence of equilibrium will conclude the section.

\subsection{Environment}

Time is continuous and the horizon is infinite. The economy starts with a unit measure of agents denoted by $i \in(0,1)$. Agents discount the future at rate $\beta$ and their instantaneous utility from consumption is given by a strictly increasing and strictly concave function $u(\cdot)$. There is also a competitive market of risk neutral creditors with access to funds at rate $r \geq \beta$.

There is a Rating Technology which sends a public signal $\tilde{\theta}(i)$ about each agent's risk type $\theta(i)$ at the beginning of the economy. Then each agent $i$ realizes her type $\theta(i) \in[0,1]$ which is private information. The joint distribution of types and signals, denoted by $\psi(\theta, \tilde{\theta})$ is public information.

Agents receive two streams of incomes. First, type $\theta$ agents draw their initial stream of income, $y^{I}$, from a type dependent distribution $F_{\theta}^{I}(\cdot)$. A type $\theta$ agent $i$ continues with this stream of $y^{I}(i)$ units of income till a random switching time governed by a Poisson process with a type dependent parameter $\delta_{\theta}$. Once the switching time arrives, she will draw her permanent income, $y^{P}$, from a type dependent distribution $F_{\theta}^{P}(\cdot)$, and she will receive a certain stream of $y^{P}$ units of income for the rest of her life. We assume the support of $y^{I}$ and $y^{P}$ are uniformly bounded away from zero for all types. ${ }^{24}$ Moreover, assume $F_{\theta} P(\cdot)$ does not have any mass point. Agent's incomes are publicly observable.

Agents can borrow from the credit market, but cannot save. Lending contracts can only be made at the beginning of the economy after receiving the public signals about agents types and before the agents realize their initial incomes. Agents are only allowed to contract with a single creditor from the pool of competitive creditors. Creditors are committed to their contracts with each agent till she realizes her permanent income at which point the contracts can be renegotiated in the competitive market. Lending contracts are constrained to have a fixed interest rate $\rho$ and a credit limit $L$; that is their debt will accumulate at interest rate $\rho$ and can increase up to $L$. After realization of $y^{P}$ agents can make new credit contracts.

At any point in time, agents are allowed to exercise their option of bankruptcy. If an agent files for bankruptcy, all of her debt will be forgiven but she cannot borrow from the credit market anymore. Moreover, after filing for bankruptcy, agent $i$ can only consume $\theta(i) \in[0,1]$ fraction of her income from that time on.

\footnotetext{
${ }^{22}$ For an elaborate model of credit card usage with Markovian income process, see Chatterjee, Corbae, Nakajima and Rios-Rull [10]

${ }^{23}$ Chatterjee et al. [10] uses this approach.

${ }^{24}$ That is $\exists \epsilon>0$ such that $F_{\theta}^{I}(\epsilon)=F_{\theta}^{P}(\epsilon)=0 \forall \theta$.
} 
To summarize, at the beginning of the economy a competitive credit market receives a signal about each agent's type, and offers a credit contract which consists of a fixed interest rate and a credit limit. Then, the agents realize their type and initial income and start using their credit line until they realize their permanent income. At any point agents can default on their debt which will cause them to lose a fraction of their income for the rest of their life.

\subsection{Agent's Problem}

Given the offered credit contract, which we denote by the pair of credit limit and interest rate $(L, \rho)$ and after realizing type, $\theta$, and initial income, $y^{I}$, agents decide on how much to borrow/pay on their credit lines, and whether to file for bankruptcy or not. In particular, at the beginning of time an agent can choose $b(t)$, the amount of borrowing/payment on her credit line if she doesn't switch to her permanent income by time $t$, and whether to default on her debt at time $t$ if she has not realized $y^{P}$ by that time. Since agents can only default once, we can denote the time of filing for bankruptcy by $T^{*}$. That is, if the agent's income does not switch to $y^{P}$ by time $T^{*}$ she defaults at that time. Obviously agents can choose to not default on their debt before switching to permanent income, in which case $T^{*}$ is set to infinity. by:

The sequential problem for a type $\theta$ agent who has realized income $y^{I}$ and is offered contract $(L, \rho)$ is given

$$
V^{I}\left((L, \rho) ;\left(\theta, y^{I}\right)\right)=\max _{b(t), T^{*}}\left\{\begin{array}{r}
\int_{0}^{T^{*}} e^{-\left(\delta_{\theta}+\beta\right) t}\left[u\left(y^{I}+b(t)\right)+\delta_{\theta} V^{P}(D(t) ; \theta)\right] d t \\
+\int_{T^{*}}^{\infty} e^{-\left(\delta_{\theta}+\beta\right) t}\left[u\left(\theta y^{I}\right)+\delta_{\theta} V^{D}(\theta)\right] d t
\end{array}\right\}
$$

where the debt level at time $t<T^{*} \leq \infty$, denoted by $D(t)$, must satisfy the credit limit constraint:

$$
D(t)=\int_{0}^{t} e^{\rho(t-\tau)} b(\tau) d \tau \leq L
$$

$V^{P}(D ; \theta)$ is the expected value of realizing the permanent income for a type $\theta$ agent with debt level $D$, and $V^{D}(\theta)$ is the expected value of realizing the permanent income for a type $\theta$ agent who has defaulted on her debt and filed for bankruptcy before realizing her permanent income.

In particular, the expected value of realizing the permanent income after default is:

$$
V^{D}(\theta)=\frac{1}{\beta} \int u\left(\theta y^{P}\right) d F_{\theta}^{P}\left(y^{P}\right) .
$$

When a type $\theta$ agent with $D$ units of debt realizes her permanent income $y^{P}$, which is observable by the credit market, since $r \geq \beta$ she has no incentive to borrow from the credit market without the intention of defaulting on it. Hence the creditors will not allow her to use the remaining of her credit line after realizing her permanent income. Thus the agent has to decide on paying back her debt or to default on it. If the agent files for bankruptcy, the present value of her utility from consuming $\theta$ of the stream of her income is:

$$
\frac{1}{\beta} u\left(\theta y^{P}\right)
$$

If the agent decides to pay back her debt, since there is no uncertainty about her future income for the competitive credit market, the charged interest rate will be set at $r$. Then her problem is choosing the stream of payment amount $p$ to maximize the present value of her consumption given by:

$$
\max _{p} \int_{0}^{\infty} e^{-\beta t} u\left(y^{P}-p\right) d t
$$


subject to $\dot{D}=r D-p$. The Hamiltonian for this problem is given by:

$$
\mathcal{H}=e^{-\beta t} u\left(y^{P}-p\right)+\lambda(r D-p)
$$

which yields the solution $\dot{p}=(r-\beta) \frac{\left.u^{\prime}\left(y^{P}-p\right)\right)}{\left.u^{\prime \prime}\left(y^{P}-p\right)\right)}$. In the case of $r=\beta$, the solution is given by $p=r D$, and hence the present value of the agent's utility is given by:

$$
\frac{1}{\beta} u\left(y^{P}-r D\right) .
$$

In this case, if $y^{P}-r D \geq \theta y^{P}$ the agent will choose to consolidate her debt at interest rate $r$ and pay it back, otherwise she will default on her debt and consume $\theta y^{P}$ for the rest of her life. Therefore for $r=\beta$ we have:

$$
V^{P}(D ; \theta)=\frac{1}{\beta}\left[\int_{0}^{\frac{r D}{1-\theta}} u\left(\theta y^{P}\right) d F_{\theta}^{P}\left(y^{P}\right)+\int_{\frac{r D}{1-\theta}}^{\infty} u\left(y^{P}-r D\right) d F_{\theta}^{P}\left(y^{P}\right)\right] .
$$

Agents have three decision to make: (i) whether to default or pay back their debt after realizing their permanent income, (ii) whether to default or not before realizing the permanent income, that is to set $T^{*}<\infty$ or $T^{*}=\infty$, and (iii) the sequence of borrowing/payment $b(t)$.

If agent decides to default before realizing her permanent income, she does not do so before using all of her available credit limit, or otherwise she can continue borrowing and default later. ${ }^{25}$ Let's denote the time of reaching the credit limit by $T$. Then if the agent defaults before realizing her permanent income, that is $T^{*}<\infty$, then $T=T^{*}$. Later we will show under certain conditions that $T$ is finite, that is even if $T^{*}=\infty$ and the agent does not default before switching to the permanent income, she will reach her credit limit in finite time if she does not realize her permanent income for that long.

Let's denote the agent's borrowing at the time of reaching her credit limit by $b^{*}=b(T)$. If the agent does not default at the limit, she has to pay the interest charge of her debt to satisfy the credit limit, that is $b^{*}=-\rho L$. So if the agent does not default after reaching the credit limit the continuation value from (1) is equal to

$$
\frac{1}{\delta_{\theta}+\beta}\left[u\left(y^{I}-\rho L\right)+\delta_{\theta} V^{P}(L ; \theta)\right] .
$$

But if she defaults the continuation value will be

$$
\frac{1}{\delta_{\theta}+\beta}\left[u\left(\theta y^{I}\right)+\delta_{\theta} V^{D}(\theta)\right]
$$

So the agent defaults at the credit limit only if:

$$
\left[u\left(\theta y^{I}\right)+\delta_{\theta} V^{D}(\theta)\right]>\left[u\left(y^{I}-\rho L\right)+\delta_{\theta} V^{P}(L ; \theta)\right]
$$

Now if (5) holds and the agent defaults at the limit, then $b^{*}=b(T)=b\left(T^{*}\right) \geq-\rho L$. In general:

Lemma 1 Agent's borrowing/payment at the credit limit, $b^{*}=b(T) \geq-\rho L$, satisfies:

$$
u^{\prime}\left(y^{I}+b^{*}\right) \leq \frac{\left[u\left(y^{I}+b^{*}\right)+\delta_{\theta} V^{P}(L ; \theta)\right]-\left[u\left(\theta y^{I}\right)+\delta_{\theta} V^{D}(\theta)\right]}{\rho L+b^{*}}
$$

with equality if $b^{*}>-\rho L$. Moreover, if (5) holds then (6) uniquely determines $b^{*}$.

\footnotetext{
${ }^{25}$ Notice that even if she realizes her permanent income the option of default is still available for her.
} 
Proof. See the Appendix.

In short, the left hand side of (6) is the marginal benefit of consumption for an agent just before she reaches her credit limit. The numerator of the right hand side is the difference between the stream of utility before and after default, and the denominator is the rate of debt increase (or equivalently the rate of approaching the limit as the time of default.) Overall the right hand side of (6) is the marginal cost of approaching the event of default due to increasing consumption.

Now knowing the agents decision at her credit limit and whether she defaults or not at the limit let's study her borrowing decision before reaching the limit. The Hamiltonian for the agent's problem (1) before reaching the limit is given by:

$$
\mathcal{L}=e^{-\left(\delta_{\theta}+\beta\right) t}\left[u\left(y^{I}+b\right)+\delta_{\theta} V^{P}(D ; \theta)\right]+\lambda[\rho D+b],
$$

and the optimal solution must satisfy:

$$
\begin{aligned}
& \frac{\partial \mathcal{L}}{\partial \lambda}=\rho D+b=\dot{D} \\
& \frac{\partial \mathcal{L}}{\partial D}=e^{-\left(\delta_{\theta}+\beta\right) t} \delta_{\theta} V^{P}(D ; \theta)+\rho \lambda=-\dot{\lambda} \\
& \frac{\partial \mathcal{L}}{\partial b}=e^{-\left(\delta_{\theta}+\beta\right) t} u^{\prime}\left(y^{I}+b\right)+\lambda=0
\end{aligned}
$$

We have the solution for $b(T)$ from (6) which implies the $\lambda(T)$ from (10). Now solving for $\lambda$ backward from (9) and then substituting it in (10) for $t<T$ we have:

$$
\begin{aligned}
u^{\prime}\left(y^{I}+b(t)\right)= & e^{-\left(\delta_{\theta}+\beta-\rho\right)(T-t)} u^{\prime}\left(y^{I}+b(T)\right) \\
& -\int_{t}^{T} \delta_{\theta} e^{-\left(\delta_{\theta}+\beta-\rho\right)(\tau-t)} V_{D}^{P}(D(\tau) ; \theta) d \tau .
\end{aligned}
$$

The left hand side of (11) is the marginal utility from increasing debt level at time $t$. The right hand side gives us the two marginal costs associated with increasing debt level. The first expression is the marginal cost associated with getting closer to the limit, hence being credit constrained, and the second expression is the marginal cost of debt level if the agent realizes her permanent income before reaching the limit.

Figure (4) helps to see the marginal costs. If the agent increases her borrowing for a small period of time but does not alter it for the rest, then she will reach the credit limit sooner. This is depicted by the altered debt level reaching the credit limit sooner than the original debt level. The agent's consumption for the period of time just before when she used to reach the credit limit declines. On the other hand if the agent realizes her permanent income before reaching the limit, with the altered borrowing, she will carry more debt which is more costly to pay back.

Notice that we can also consider the borrowing/payment amount, $b$, as a function of the outstanding debt, $D$, and the credit contract $(L, \rho)$. That is $b(t)=b(D(t) ;(L, \rho))$. Then by taking the derivative of (10) with respect to time and then substituting for $\dot{\lambda}$ from (9) we have:

$$
\frac{d b(D ;(L, \rho))}{d D}=\frac{\dot{b}}{\dot{D}}=\frac{\left(\delta_{\theta}+\beta-\rho\right) u^{\prime}\left(y^{I}+b\right)+\delta_{\theta} V_{D}^{P}(D ; \theta)}{u^{\prime \prime}\left(y^{I}+b\right)(\rho D+b)}
$$

Using $b(L ;(L, \rho))=b^{*}$ from (6) as the boundary condition, we can find $b(D ;(L, \rho))$ for $\forall D<L$ by solving the differential equation (12). Moreover, we can use this approach to state some properties of the borrowing/payment function.

Lemma $2 b(D ;(L, \rho))$ is continuous in debt level, $D$, credit line, $L$, and interest rate $\rho$. 


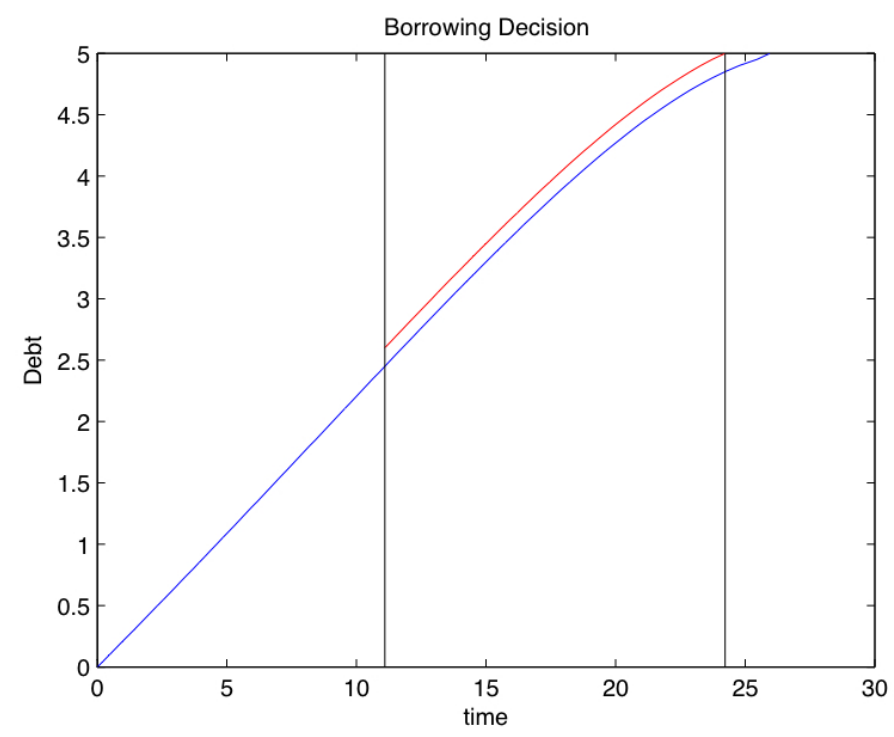

Figure 4: Change of Borrowing Decision

Proof. By construction $b(L ;(L, \rho))=b^{*}$ is continuous from (6). The continuity of $b(D ;(L, \rho))$ for $D<L$ follows from continuity of the solution for the differential equation (12).

Lemma 3 For $L_{1}<L_{2}$, if the agent's solution for (1) finds it optimal to increase the debt level up to the limit then:

$$
b\left(L_{1} ;\left(L_{1}, \rho\right)\right)<b\left(L_{1} ;\left(L_{2}, \rho\right)\right) .
$$

Proof. See the Appendix.

Theorem 4 If the agent's solution for (1) finds it optimal to increase the debt level up to the limit then $b(D ;(L, \rho))$ is strictly increasing in $L$.

Proof. Suppose not, then $\exists D^{*}$ and $L_{1}<L_{2}$, such that

$$
b\left(D^{*} ;\left(L_{1}, \rho\right)\right) \geq b\left(D^{*} ;\left(L_{2}, \rho\right)\right) .
$$

Since $b\left(L_{1} ;\left(L_{1}, \rho\right)\right)<b\left(L_{1} ;\left(L_{2}, \rho\right)\right)$ then by continuity $\exists D^{* *}$ such that

$$
b\left(D^{* *} ;\left(L_{1}, \rho\right)\right)=b\left(D^{* *} ;\left(L_{2}, \rho\right)\right)
$$

. But in that case (12) implies

$$
b\left(D ;\left(L_{1}, \rho\right)\right)=b\left(D ;\left(L_{2}, \rho\right)\right) \quad \forall D \geq D^{* *}
$$

which contradicts $b\left(L_{1} ;\left(L_{1}, \rho\right)\right)<b\left(L_{1} ;\left(L_{2}, \rho\right)\right)$.

The theorem state that when agents are offered higher credit limits they will accumulate more debt. This point can be seen in figure(5). With the credit limits depicted in this figure, agents do not default after reaching the credit limit and pay back the interest charge of their debt, waiting for the realization of their permanent income. Notice that with higher credit limit it takes longer for the agent to reach the limit. Moreover, as time passes and agents accumulate debt, their borrowing declines. Following (11) there are two factors contributing to the curbing of borrowing. First as the debt level goes up agents get closer to the credit limit which makes her borrowing 


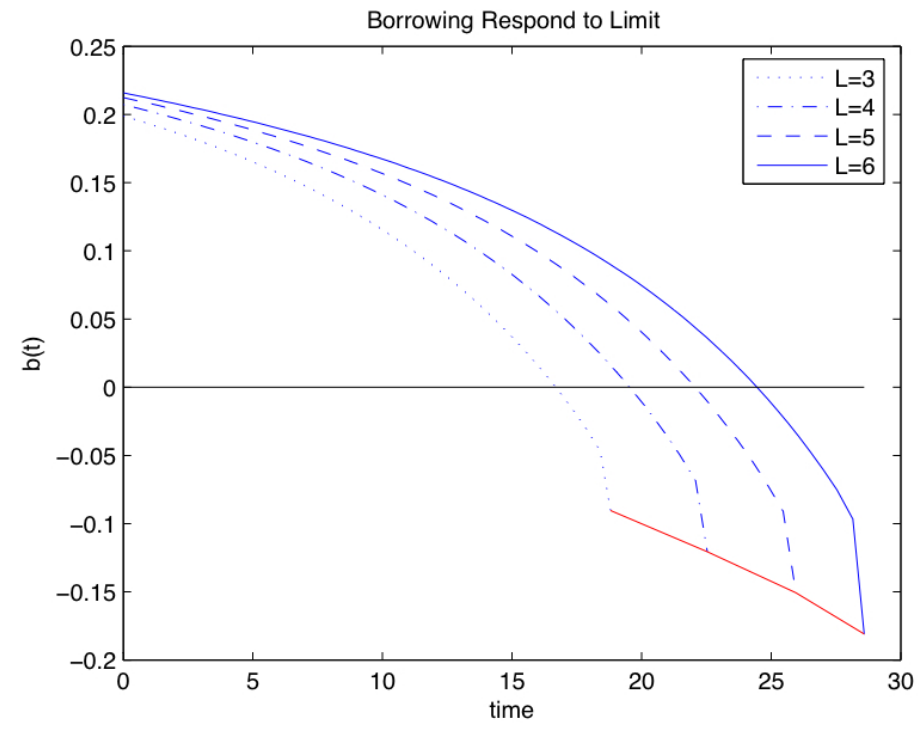

Figure 5: Borrowing with Different Credit Limits

constrained. Second as debt accumulates the marginal cost of debt after switching to the permanent income increases, hence making it more costly to borrow. Although the first factor is always in place, the second one may not.

Figure (6) shows the borrowing schedule for two close credit limits where with the lower one the agent does not default after reaching the limit but with the higher limit she finds the default option optimal once her debt level equals the credit limit. ${ }^{26}$ This figure also depicts another important fact. Although eventually as the agent approaches her credit limit she curbs her borrowing due to the first factor described above, at the beginning as time passes and the debt level increase, the agent might actually increases her borrowing. This is because the second factor explained above is not in place. That is the marginal cost of debt after switching to the permanent income is actually shrinking.

Notice that as the debt level goes up, as long as the agent is not going to default on the debt after switching to her permanent income, the marginal cost of paying back also increases due to concavity of the utility function. But if the agent defaults after switching to the permanent income, then as the debt level rises the probability of paying back falls. Denote the lower bound for the support of $y^{P}$ 's distribution by $y^{P}$. We can summarize this fact in the following lemma.

Lemma 5 If $r=\beta$, then $V_{D}^{P}(D ; \theta)$ is decreasing in $D$ for $D \in\left[0, \frac{\underline{y}^{P}(1-\theta)}{r}\right]$ and increasing for $D>\frac{\underline{y}^{P}(1-\theta)}{r}$.

Proof. See the Appendix.

Notice that so far we have simply assumed that the agent continues to accumulate debt untill reaching the credit limit. But what if the charged interest rate $\rho$ is so high, or the agent does not expect very high permanent income, such that she does not find increasing the debt level up to the credit limit optimal? In particular if the solution for (12) is such that $\exists D<L$ where $b(D ;(L, \rho))=-\rho D$, then the agent stops borrowing after reaching

\footnotetext{
${ }^{26}$ The figure shows that there are times when the agent borrows more with the lower credit limit. This is because the agent has accumulated much more debt by that time when she has a higher limit, and for $L_{1}<L_{2}$ we still have

$$
b\left(D ;\left(L_{1}, \rho\right)\right)<b\left(D ;\left(L_{2}, \rho\right)\right)
$$
}




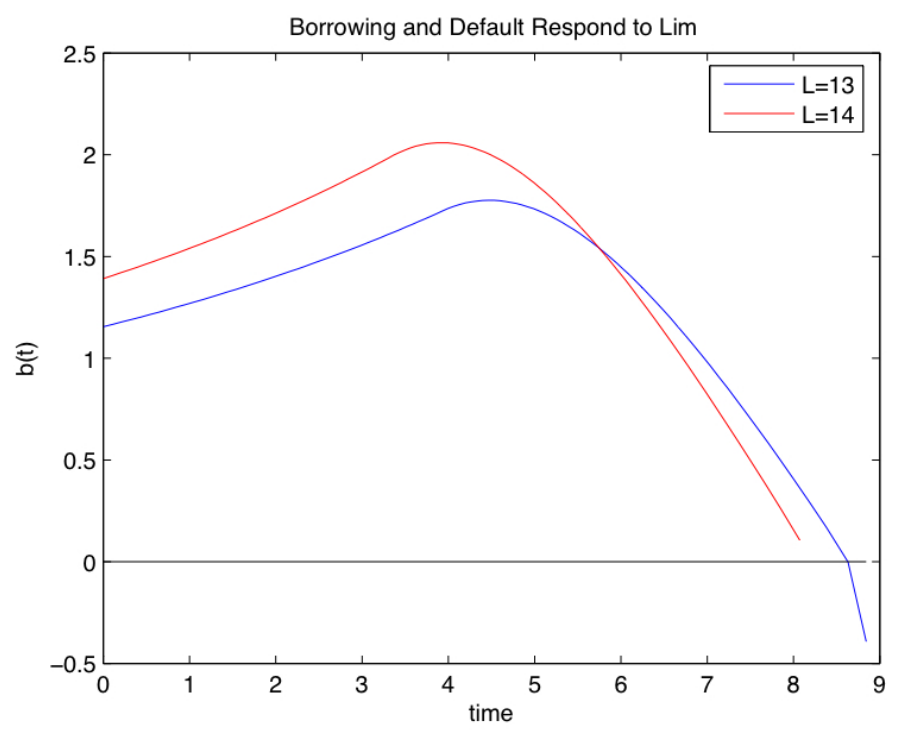

Figure 6: Borrowing and Default with Different Credit Limits

to the debt level $D$. The following lemma provides a sufficient condition for optimality of borrowing up the credit limit.

Lemma 6 For $r=\beta$, if $\left(\delta_{\theta}+\beta-\rho\right) u^{\prime}\left(y^{I}\right)+\delta_{\theta} V_{D}^{P}\left(\frac{\underline{y}^{P}(1-\theta)}{r} ; \theta\right)>0$ then the agent does not stop increasing her debt before getting to the credit limit.

Proof. See the Appendix.

Notice that this condition is independent of the credit limit, $L$. However, it depends on the contract's interest rate, $\rho$. Obviously it also depends on the initial income as well as the agent's expectation of the time of realizing the future income, $\delta_{\theta}$, the distribution of permanent income, $F_{\theta}^{P}(\cdot)$, and the cost of default $(1-\theta)$. Although the previous lemma provides a sufficient condition for the agent to continue borrowing, it doesn't say that the agent actually reaches the limit or not, which is the subject of the next theorem.

Theorem 7 For $r=\beta$, if $\left(\delta_{\theta}+\beta-\rho\right) u^{\prime}\left(y^{I}\right)+\delta_{\theta} V_{D}^{P}\left(\frac{y^{P}(1-\theta)}{r} ; \theta\right)>0$ then there exists a time $T$ such that for $t \geq T$ we have $D(t)=L$. That is, if agents do not realize their permanent income for a long enough time, then they reach the credit limit.

Proof. Suppose the agent does not reach the credit limit, then for a large enough $t$ such that $D(t) \approx L$ and $b(t) \approx-\rho L,(11)$ implies:

$$
\begin{aligned}
u^{\prime}\left(y^{I}+b(t)\right) & =-\int_{t}^{\infty} \delta_{\theta} e^{-\left(\delta_{\theta}+\beta-\rho\right)(\tau-t)} V_{D}^{P}(D(\tau) ; \theta) d \tau \\
& \approx \frac{-\delta_{\theta}}{\delta_{\theta}+\beta-\rho} V_{D}^{P}(L ; \theta)
\end{aligned}
$$

which contradicts $\left(\delta_{\theta}+\beta-\rho\right) u^{\prime}\left(y^{I}-\rho L\right)+\delta_{\theta} V_{D}^{P}(L ; \theta)>0$.

So far, we have studied the effect of the credit limit on borrowing and debt levels, but not the default rate. From (5) the probability of default after switching to the permanent income with $D$ units of debt is given by:

$$
F_{\theta}^{P}\left(\frac{r D}{1-\theta}\right)
$$


When the agent is offered a higher credit limit (as for example depicted in figure (5)) she will accumulated more debt. Since the time of switching to the permanent income is exogenous and independent of the debt level, after switching, the probability of having higher debt level and therefore the probability of default is higher with a higher credit limit.

Agents might also default when they reach their credit limit before switching to their permanent income. This is depicted in figure (6). In this comparison the higher credit limit not only causes the agent to accumulate more debt by the time of switching, but also makes the agent reach the credit limit sooner and then default after reaching the limit.

In summary, a larger credit limit induces agents to borrow more, and hence more likely to default. Ceteris paribus, an agent with low cost of default responds more to increase of credit limit and less to rise of interest rate, than an agent with high cost of default.

\subsection{Creditors' Problem}

In the previous subsection we studied decision rules of a type $\theta$ agent who has realized initial income $y^{I}$ and is offered $(L, \rho)$ credit contract. Creditors take agents' decision rules as given. Given the agents' decision rule as a function of the offered credit contract, creditors' expected profit from offering contract $(L, \rho)$ to a type $\theta$ agent with initial income $y^{I}$ is given by:

$$
\Pi\left(\left(\theta, y^{I}\right) ;(L, \rho)\right)=\int_{0}^{T^{*}} e^{-\left(\delta_{\theta}+r\right) t}\left[-b(t)+\delta_{\theta} D(t)\left(1-F_{\theta}^{P}\left(\frac{r D(t)}{1-\theta}\right)\right)\right] d t
$$

where $b(t)$ and $T^{*}$ are the borrowing and default time decisions which solve (1) for a type $\theta$ agent with initial income $y^{I}$ who is offered credit contract $(L, \rho)$. Moreover $D(t)$ is the implied debt amount from (2). Notice that when the agent switches to her permanent income with debt level $D(t)$, the probability of paying back her debt is $1-F_{\theta}^{P}\left(\frac{r D(t)}{1-\theta}\right)$ from (13).

When a creditor in the competitive credit market offers a credit contract, the only available information is the public signal $\tilde{\theta}$ from the Rating Technology. Agents have not realized their types nor their initial incomes yet. Denoting the conditional probability of drawing type $\theta$ given the signal $\tilde{\theta}$ by $\psi(\theta \mid \tilde{\theta})$, a creditor's expected profit from offering credit contract $(L, \rho)$ to an agent with rating signal $\tilde{\theta}$ is:

$$
\Pi(\tilde{\theta} ;(L, \rho))=\iint \Pi\left(\left(\theta, y^{I}\right) ;(L, \rho)\right) d F_{\theta}^{I}\left(y^{I}\right) d \psi(\theta \mid \tilde{\theta}) .
$$

Recall that when agents are offered the credit contract, they have not realized their type and income yet, however, they are also aware of the rating signal. Expected utility of an agent with the rating signal $\tilde{\theta}$ from contract $(L, \rho)$ is given by:

$$
V^{I}((L, \rho) ; \tilde{\theta})=\iint V^{I}\left((L, \rho) ;\left(\theta, y^{I}\right)\right) d F_{\theta}^{I}\left(y^{I}\right) d \psi(\theta \mid \tilde{\theta}) .
$$

Since we assumed there is no asymmetry of information between agents and creditors when credit contracts are made, the only contract offered and accepted will be the one which delivers the highest expected utility subject to zero profit. That is the offered contract for an agent with rating signal $\tilde{\theta}$ must solve the following creditors' problem: 


$$
\begin{array}{cc} 
& \max _{(L, \rho)} V^{I}((L, \rho) ; \tilde{\theta}) \\
\text { s.t. } & \Pi(\tilde{\theta} ;(L, \rho))=0 .
\end{array}
$$

Notice that when the signals are not very informative and hence agents with different types and incomes are lucked into the same contract, then some types generate positive profit which is used to compensate the losses made on other types. Moreover, lack of information causes another inefficiency: there are several pairs of $(L, \rho)$ which can generate zero profit from a type $\theta$ agent with initial income $y^{I}$, but when agents with different characteristics are pooled and offered the same contract, they do not receive the efficient contracts.

Figure(7) shows how a creditor's profit changes as she increases the offered credit limit for a fix interest rate $\rho>r$. The figure depicts profit from two different types with the same initial income. For illustrative purpose I have assumed the two types have an identical distribution of permanent incomes and the same switching process, so their only difference is with respect to their default costs. As the limit increases the creditor's profit rises, since agents can borrow more but yet do not find it optimal to default on their debt, hence for $\rho>r$ the creditor's expected profit rises. For a large enough credit limit, the riskier agent accumulates enough debt to find it optimal to default, and creditors' profit from her falls. However, the safer agent still generates more profit. By increasing the credit limit eventually the safer agent also accumulates enough debt to find the default option optimal. This makes the expected profit from her to fall as well. Next section provides sufficient conditions under which solution for the creditor's problem (17) exists.

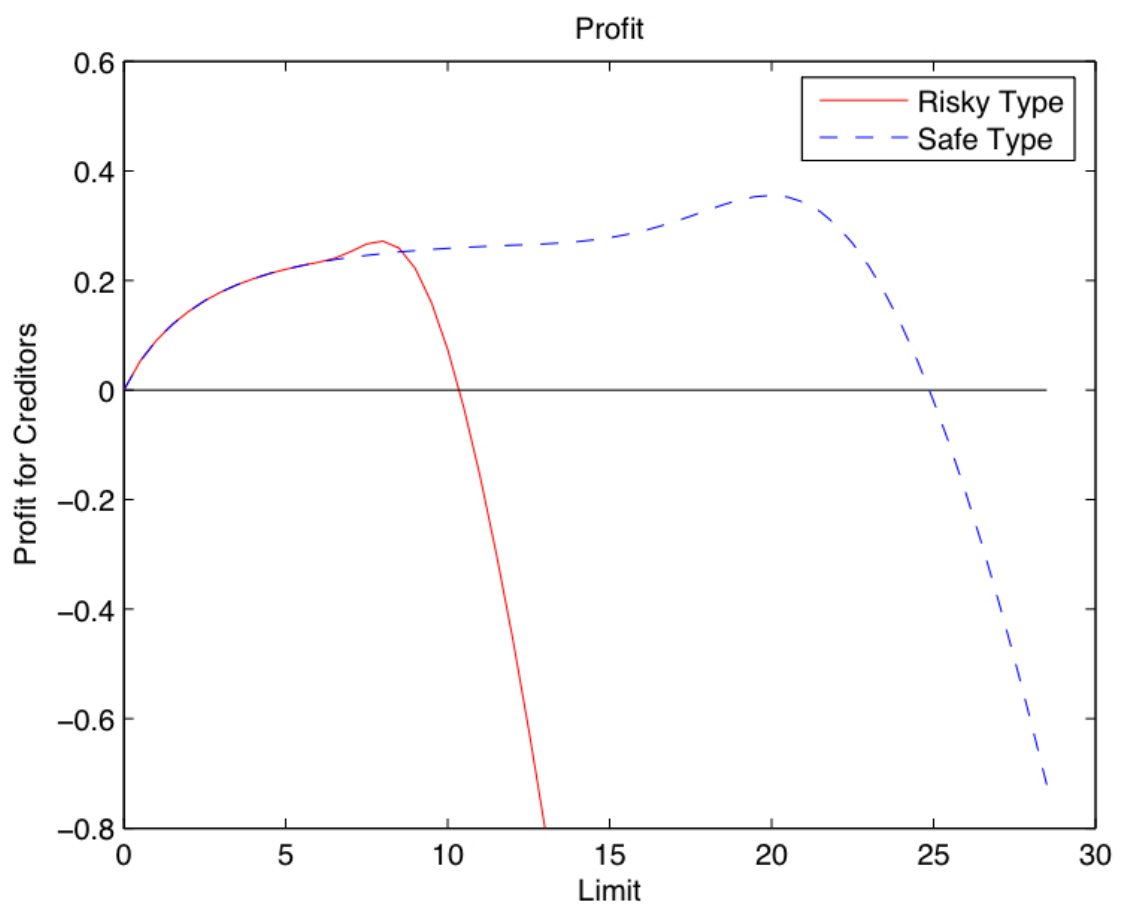

Figure 7: Creditors' Profit 


\subsection{Equilibrium Existence}

In this part we show the existence of equilibrium, which is characterized by the solution for creditors' problem (17) of offering credit contract $(L, \rho)$ to an agent with rating signal $\tilde{\theta}$.

Lemma $8 \Pi\left(\left(\theta, y^{I}\right) ;(L, \rho)\right)$ is continuous in $L$ and $\rho$.

Proof follows from the continuity of the decision rule $b$ and lack of mass points in $F_{\theta}^{P}(\cdot)^{27}$.

Lemma 9 If the support of $\psi(\cdot \mid \tilde{\theta})$ is bounded away from zero, the utility function $u(\cdot)$ is unbounded from above and the expected present value of all future income for an agent with signal $\tilde{\theta}$ is bounded then:

$$
\lim _{L \rightarrow \infty} \Pi(\tilde{\theta} ;(L, \rho))<0 \forall \rho .
$$

Proof. See the Appendix.

The proof first shows for any $\rho \geq r$ we have $\lim _{L \rightarrow \infty} V^{I}((L, \rho) ; \tilde{\theta}) \rightarrow \infty$. Then uses the fact that with $\Pi(\tilde{\theta} ;(L, \rho)) \geq 0$ the expected utility $V^{I}((L, \rho) ; \tilde{\theta})$ is bounded from above.

Theorem 10 If the support of $\psi(\cdot \mid \tilde{\theta})$ is bounded away from zero, the utility function $u(\cdot)$ is unbounded from above and the expected present value of all future income for an agent with signal $\tilde{\theta}$ is bounded then creditors' problem (17) has solution.

Proof. See the Appendix.

The idea of proof follows from defining $L^{*}(\tilde{\theta} ; \rho)$ as the largest $L$ such that $\Pi(\tilde{\theta} ;(L, \rho))=0$. Then showing $V^{I}\left(\left(L^{*}(\tilde{\theta} ; \rho), \rho\right) ; \tilde{\theta}\right)$ attains its maximum.

\section{Discussion and Quantitative Example}

As stated in the previous section, when a contract is offered, neither the agent nor the creditor know the agent's true type. The only available information upon which a contract can be made contingent is the exogenous signal from the Rating technology. Therefore, contracts in my environment are only conditional on rating signals. That is, agents with identical signals will receive contracts with identical terms. However, after realization of types and initial incomes, agents with the same contract may choose different borrowing patterns. Moreover, the heterogeneous arrival and level of realized permanent incomes lead agents with identical contracts, type and initial income to accumulate different levels of debt and make different default decisions.

Although the model is general enough to allow both the credit limit and interest rate to be signal dependent, for the purpose of this discussion and the quantitative example, I make an assumption which is consistent with data. I assume credit contracts are all subject to a fixed interest rate $\rho>r$, and the only difference among types is in their cost of default. In this case the only variation across contracts for different signals will be in their credit limits. Suppose different types are pooled together by the Rating technology, which is possible if the signals are not very informative about agents' types. In equilibrium agents will receive a credit limit which makes creditors' expected profit from the pooling contract equal to zero. The agents with a low cost of default will generate negative profit which will be compensated by the positive profit generated by the agents with high cost of default. Notice that since agents do not know their type at the time they choose from the offered contracts, and are not allowed to change their contract after realization of their type and initial income, at the time contracts are offered they have the same preference over the set of offered contracts. Therefore creditors cannot separate different types of agents within the pool of agents with identical Rating signals by offering different contracts.

\footnotetext{
${ }^{27}$ When the supplied credit limit is such that the agent is indifferent between default or staying at the limit after reaching the credit limit, then creditor's profit depends on the fraction of agents who default after reaching the limit. Therefore $\Pi\left(\left(\theta, y^{I}\right) ;(L, \rho)\right)$ is a correspondence of $L$, however, a continuous one
} 
Moreover, since the agents with high cost of default are more likely to pay back their debt, the marginal cost of borrowing is higher for them relative to the agents with a low cost of default. Therefore, with the same credit limit the high default cost agents accumulate lower levels of debt, and the responsiveness of their debt level to an increase of their credit limit is also smaller. This prevents creditors from raising the credit limit in the pooling case. Because if the credit limit is increased, then loans taken by low default cost agents which make negative expected profits will increase more than loans taken by high default cost agents which make positive expected profits.

Now suppose different types are separated by the Rating technology, which is possible if the signals are informative about agents' types. While in the pooling case there is cross subsidization across types, in the separating case the profit gain from high default cost type cannot be used to subsidize the loss made on low default cost type. In that case, the equilibrium supply of credit will increase significantly for the high default cost agents. Since the interest rate is assumed to be fixed, competitive creditors extend the credit limit for high default cost agents until a level where some of them increase their debt level high enough to find it optimal to default.

In the next subsection, I provide a quantitative example of the model to account for the increase in the average credit limit and credit card debt, as well as the rise in the number of bankruptcies observed from 1992 to 1998. In this quantitative example the mechanism which matches the data can be thought of as an increase in the intensive margin and not the extensive margin. Afterward, I will provide an explanation for the increase of extensive margin of credit supply.

\subsection{Quantitative Example}

Most of the households with positive credit limits do not borrow on their credit cards (see the last row of table (1)). Therefore I restrict my attention to revolvers, who have positive debt on their credit cards. The model predicts that households first increase their credit card debt before realizing their permanent income, then either default on their debt or pay it back. The SCF is not a panel data set so I could not use it to observe the dynamics of households' credit card debt accumulation or de-accumulation. The SCF, however, reports households' answer to the following question:

Thinking only about Visa, Mastercard, Discover, Optima and store cards, do you almost always, sometimes, or hardly ever pay off the total balance owed on the account each month?

Roughly speaking, half of the revolvers answer "they hardly ever pay off the total balance." This group of households are those who are accumulating credit card debt and I call them A-revolvers. The last row of table (3) reports the fraction of A-revolvers from all households in the SCF 1992 and 1998. The first and third rows report average ratios of credit limit and credit card debt of A-revolvers to their annual income. ${ }^{28}$ The standard deviations of the distributions of ratios of credit limits and credit card debt of A-revolvers to their incomes are also reported. The next row reports the fraction of A-revolvers who filed for bankruptcy, assuming all filers are also A-revolvers.

Since the fraction of A-revolvers in the population increased, looking at the ratio of defaulters to A-revolvers underestimates the rise of bankruptcy filings. However, the result of this quantitative exercise is not sensitive to using the ratio of defaulters to the average number of A-revolvers across two years.

For this exercise I assume the utility function to have constant relative risk aversion, that is $u(c)=\frac{c^{1-\sigma}-1}{1-\sigma}$. The switching process from the initial income to permanent income follows a Poisson process with parameter $\delta$ for all types. The initial income is fixed for all types and the permanent income is drawn from a truncated exponential distribution:

$$
F\left(y^{P}\right)=1-e^{-\eta\left(y^{P}-\underline{y^{P}}\right)}
$$

for all types. Finally I assume there are two types $0<\theta_{L}<\theta_{H}<1$ with distribution $\mu\left(\theta_{L}\right)=1-\mu\left(\theta_{H}\right)$.

In order to highlight the role of changes in the information technology, I will consider two cases. In the first one the signal from the Rating technology contains no information on agents' types so we have complete pooling

\footnotetext{
${ }^{28}$ This figures are reported after dropping less than half percentage of the subsample who report zero or negative income. I also tried the exercise with the average credit limit and credit card debt of A-revolvers divided by their average annual income. The results are very similar
} 


\begin{tabular}{r|rr} 
A-revolvers & 1992 & 1998 \\
\hline Av. (Cred Lim/Income) & $25.97 \%$ & $42.48 \%$ \\
Std. (Cred Lim/Income) & $41.38 \%$ & $77.50 \%$ \\
Av. (Cred Card Debt/Income) & $10.66 \%$ & $16.95 \%$ \\
Std. (Cred Card Debt/Income) & $17.61 \%$ & $35.46 \%$ \\
Default Rate & $5.86 \%$ & $7.39 \%$ \\
\hline A-revolvers/Population & $16.05 \%$ & $17.31 \%$
\end{tabular}

Table 3: Target Moments

of the two types. In the second case, I assume the signal is fully informative so we have complete separation and each type will receive a different contract.

I try to match the moments generated by the model in the pooling case to the data moments from 1992, and the moments generated by the model in the separating case to the data moments from 1998. Clearly the Rating technology provided some information on households' type in 1992, and did not provide full information in 1998. In particular, households were not offered a single credit card contract in 1992 as the model suggests in the pooling case. Instead, a distribution of credit card limits were supplied by the creditors in 1992. However, the spread of the distribution of credit limits increased from 1992 to 1998. In this quantitative exercise I try to account for the increase of the spread of the distribution of credit limits as a result of a more informative Rating technology ${ }^{29}$.

In the pooling case, both types are offered a single credit limit $L_{P}$, while in the separating case two credit limits, $L_{S}^{\theta_{L}}$ and $L_{S}^{\theta_{H}}$, are offered. The 1992 data provides a distribution of credit limits. To study the increase of the spread of the credit limit distribution from 1992 to 1998, suppose any credit limit $L$ from the distribution of credit limits in 1992 was replaced by two credit limits $\frac{L_{S}^{\theta_{L}}}{L_{P}} L$ and $\frac{L_{S}^{\theta_{H}}}{L_{P}} L$ with weights $\mu\left(\theta_{L}\right)$ and $\mu\left(\theta_{H}\right)$ for the distribution of credit limits for 1998. In this case, the following would hold for the coefficients of variation for these three distributions:

$$
C V\left(L_{1998}\right)^{2}+1=\left(C V\left(L_{1992}\right)^{2}+1\right)\left(C V\left(L_{S}\right)^{2}+1\right)
$$

where $L_{1992}$ and $L_{1998}$ are the distribution of credit limits in 1992 and 1998, $L_{S}$ is the distribution of credit limits in the separating case, and $C V(\cdot)=\frac{\sigma(\cdot)}{\mu(\cdot)}$ is the coefficient of variation.

Taking the time unit to be 3 months, I calibrate $\beta=r=\ln (.01)$ to be consistent with the $4 \%$ average annual growth rate. I set $\rho=\ln (.03)$ to be consistent with a $12 \%$ interest charge on credit lines. ${ }^{30}$ I set the coefficient of risk aversion to be equal to 1 . I set $y^{I}$ to be the average quarterly income of A-revolvers from the SCF which is $\$ 10,000 .{ }^{31}$

\begin{tabular}{cccc}
$\beta$ & $\rho$ & $\sigma$ & $y^{I}$ \\
\hline $\ln (0.01)$ & $\ln (0.03)$ & 1 & $\$ 10,000$
\end{tabular}

I estimate the three parameters related to permanent income plus the three parameters related to the default cost and its distribution to match six target moments. Four of the moments are the average ratios of credit limits

\footnotetext{
${ }^{29}$ If the Rating technology sent signals about certain risk characteristics of borrowers in 1992 , by 1998 the signals still contained the information about those characteristics. However, as the Rating technology became more informative, it could provide some additional information about the risk characteristics of borrowers. We can interpret the switch from the pooling case (uninformative signal) to the separating case (fully informative signal) as the provision of additional information by the Rating technology on borrowers.

${ }^{30}$ Notice that the average credit card interest rate in this period is around $14.50-15.00 \%$. However, since the model generates the equilibrium credit limits by equalizing creditors' profit to zero, we should consider creditors operational costs. I approximate this cost to be $3 \%$ from the difference between the Bank Prime Loan Rate and the Federal Fund Rate.

${ }^{31}$ Since I use log utility and the target moments are ratios relative to income, this variable is not important.
} 
to income and credit card debt to income for 1992 and 1998. The fifth target moment is the default rate of the A-revolvers in 1992. The last moment to match is the coefficient of variation of the credit limits in the separating case implied from 1992 and 1998 data by (18). The last target moment captures the increase in the spread of the credit limit distribution from 1992 to 1998 . Notice that the exercise does not target the default rate of the A-revolvers in 1998.

An identity weight matrix is used to minimize the percentage deviation of the moments generated from the model from the targeted moments, which provides us with a consistent estimator. The estimated values are as follows and the moments generated from the model are reported in table (4) (the targeted values are inside the parentheses).

\begin{tabular}{cccccc}
$\delta$ & $\underline{y}^{P}$ & $\eta$ & $\theta_{H}$ & $\theta_{L}$ & $\mu\left(\theta_{H}\right)$ \\
\hline 0.1607 & 4.9635 & 0.0760 & 0.9893 & 0.9749 & 0.4251
\end{tabular}

The estimated parameters for permanent income implies on average households' permanent income is about $81 \%$ larger than their initial income, and on average it takes around one and a half years before switching to permanent income. Generally speaking this is consistent with the characteristics of the income process of households during financial distress.

\begin{tabular}{lr|rrrr} 
& & Pooling & (Data 1992) & Separating & (Data 1998) \\
\hline Target & Av. (Cred Lim/Income) & $25.87 \%$ & $(25.97 \%)$ & $42.92 \%$ & $(42.48 \%)$ \\
Moments & Av. (Cred Card Debt/Income) & $10.65 \%$ & $(10.66 \%)$ & $16.74 \%$ & $(16.95 \%)$ \\
& $\begin{array}{r}\text { Default Rate } \\
\text { Coefficient of Variation }\end{array}$ & $5.90 \%$ & $(5.86 \%)$ & & \\
& Default Rate & & & $42.78 \%$ & $(47.25 \%)$ \\
\hline $\begin{array}{l}\text { Overidentifying } \\
\text { Moments }\end{array}$ & Cred Card Debt/Income \\
of Defaulter & $10.51 \%$ & $(53.10 \%)$ & $40.40 \%$ & $(7.39 \%)$ \\
& & & & & $(70.70 \%)$
\end{tabular}

Table 4: Generated Moments

I estimate six parameters to match six moments from the data. The default rate of 1998, however, is not amongst the target moments of this exercise and hence can be used to test for consistency of the model. According to data the default rate by A-revolvers rose from $5.86 \%$ in 1992 to $7.39 \%$ in 1998 . The model generates an increase of default rate from $5.90 \%$ to $6.40 \%$, which can account for about one third of the increase in bankruptcy filings in the data. Given the simple structure of the model and the fact that the exercise did not target the increase in the bankruptcy filings the result is quite appealing.

The ratio of credit card debt to income generated by the model and reported from data are provided in the last row of table(4) (Data moments are from Sullivan et al. [21]). The average credit card debt of a defaulter generated by the model is far less than the defaulters' credit card debt reported in the data. Moreover, although the model qualitatively matches the increase in the debt level of bankruptcy filers, it generates a far bigger increase than in the data.

Table(5) reports limits, debt, default rates and average debt level of a defaulter for both types in both cases. In the pooling case agents with high default costs (i.e. the safe type) borrow very little and do not default at all. Due to their small debt level they do not compensate the creditor a lot for the loss made on the riskier agents. Hence when they are separated borrowing and default by the riskier agents does not change significantly. However, in the separating case, the safer types are offered a much larger credit limit so they accumulate larger debts and this results in more frequent default.

Although the model does relatively well in accounting for the rise of the default rate, it fails to quantitatively to match the increase of credit card debt levels of filers. This is because the safer types only default when their debt level is really high; therefore in the separating case the model generates a high level of credit card debt for the filers with the high cost of default. 


\begin{tabular}{lr|r|r} 
& & Pooling & Separating \\
\hline Low Default Cost & Lim/Income & $25.87 \%$ & $21.57 \%$ \\
$\theta_{H}$ (Risky) & Debt/Income & $15.58 \%$ & $11.68 \%$ \\
& Def Rate & $13.89 \%$ & $7.62 \%$ \\
& Def Debt/Income & $24.72 \%$ & $20.88 \%$ \\
\hline High Default Cost & Lim/Income & $25.87 \%$ & $58.71 \%$ \\
$\theta_{L}$ (Safe) & Debt/Income & $7.01 \%$ & $20.48 \%$ \\
& Def Rate & $0.00 \%$ & $5.50 \%$ \\
& Def Debt/Income & - & $54.84 \%$
\end{tabular}

Table 5: Generated Moments for Different Types

Finally I use the estimated parameters to generate a counterfactual motivated by the stigma explanation of the rise of bankruptcy. Instead of changing the information structure from pooling to separation, I keep the pooling information structure but increase the fraction of high risk types to generate the increase of bankruptcy filings equal to the separating case. This goal is attained by changing the fraction of type $\theta_{H}$ from $\mu\left(\theta_{H}\right)=42 \%$ to $\mu\left(\theta_{H}\right)=90 \%$. However, this decreases the equilibrium credit limit to $21.98 \%$ of income and the average debt level increases only slightly to $11.53 \%$ of income, both contradicting the significant increasing trends observed in the data ${ }^{32}$.

\subsection{Rise of Extensive Margin}

The model can also explain the rise of the extensive margin of credit supply. As we noted earlier, the fraction of households with access to credit cards rose from $56 \%$ in 1989 to $72 \%$ in 2004. Assume there is a type who incurs no cost after default, that is $\theta=1$. Supply of credit to this type only generates a loss for creditors and the loss is increasing in the credit limit. Now suppose a small fraction of another type $\theta^{*}<1$, who incurs some cost from default and hence does not default on a low level of debt, is pooled together with type $\theta=1$ by the Rating technology. In this pooling case, no credit will be supplied to the type $\theta^{*}$ agents who are pooled with type $\theta=1$ agents. But when the Rating technology separates the two types, these type $\theta^{*}$ agents will receive a positive credit limit.

\section{Conclusion}

This paper is a first attempt at providing an informational explanation for the rise of household bankruptcy. I simultaneously account for the increase of credit supply and the corresponding increase in average credit card debt. The extension of credit supply follows from the separation of revolvers with different degrees of riskiness. The rise of bankruptcy is explained by the increase in the availability of credit for the revolvers with high costs of default, which allows them to accumulate more credit card debt. While these revolvers are less likely to default on a low amount of debt, they default more frequently when they accumulate larger amounts of debt.

Using simulated method of moments I provide a simple quantitative example of matching the average credit limit and debt levels, as well as the increase in the spread of the credit limit distribution. The model accounts for about one third of the increase in the default rate, which is quite appealing given the simple structure of the model.

The model can be enriched by relaxing certain strong assumptions and can address other interesting questions. In particular it can be used to study why creditors find it optimal to vary the credit limit more than the interest rate. This may be informative about revolvers' income processes.

\footnotetext{
${ }^{32}$ To generate an increase in the default rate similar to the increase generated by the informational explanation, which is half of the increase observed in the data, $\mu\left(\theta_{H}\right)=42 \%$ should increase to $\mu\left(\theta_{H}\right)=55.4 \%$. In this case the equilibrium credit limit decreases to $24.28 \%$ of income, and the average debt level slightly increases to $10.92 \%$ of income, again contradicting the data trends.
} 
Understanding the rise of household bankruptcy has important policy implications. If the rise of bankruptcy filings is due to the decline of stigma, the policy response should be tightening the bankruptcy code to increase the cost of bankruptcy, similar to what the 2005 change of bankruptcy code tries to do. But if the rise of bankruptcy filings results from a more informed credit market, then tightening of bankruptcy code is not necessarily required.

Finally, Huggett [16] and Aiyagari [3] pointed out the importance of credit limits for households' precautionary saving motives and therefore the aggregate price of capital. This paper does not address household saving decisions, but tackles the question of how credit limits are allocated, which has an important role in household saving decisions and hence the aggregate capital stock. In that way, it can be used to complement the study of Chatterjee, et. al. [10] who study how bankruptcy affects the capital rate of return.

\section{References}

[1] Athreya, Kartik, 2005. "Shame as it Ever Was: Stigma and Personal Bankruptcy,"Federal Reserve Bank of Richmond Economic Quarterly, 92(2), 1-19.

[2] Ausubel, Lawrence M, 1991. "The Failure of Competition in the Credit Card Market,"American Economic Review, 81(1), 50-81.

[3] Aiyagari, S Rao, 1994. "Uninsured Idiosyncratic Risk and Aggregate Saving,"The Quarterly Journal of Economics, 109(3), 659-84.

[4] Barron, John M. and Michael Staten, 2003. "The Value of Comprehensive Credit Report: Lessons from the U.S. Experience,"'in Credit Reporting Systems and the International Economy, edited by Margaret J. Miller, 273-310. MIT Press.

[5] Berger, Allen N., 2003.

[6] Barron, John M. and Michael Staten, 2003. "The Economic Effects of Technologial Progress: Evidence from the Banking Industry,"Journal of Money, Credit and Banking, 35(2), 141-76.

[7] Calem, Paul S.; Michael B. Gorday and Loretta J. Mester, 2006. "Switching Costs and Adverse Selection in the Market for Credit Cards: New Evidence,"Journal of Banking and Finance 30(6), 1653-1685.

[8] Calem, Paul S. and Loretta J. Mester, 1995. "Consumer Behavior and the Stickiness of Credit-Card Interest Rates,"American Economic Review, 85(5), 1327-1336.

[9] Chatterjee, Satyajit; Dean P. Corbae and Jose-Victor Rios-Rull, 2005. "Credit Scoring and Competitive Pricing of Default Risk, "mimeo.

[10] Chatterjee, Satyajit; Dean P. Corbae, Makoto Nakajima and Jose-Victor Rios-Rull, 2005. "A Quantitative Theory of Unsecured Consumer Credit with Risk of Default, "Econometrica (forthcoming).

[11] Domowitz, Ian and Robert L. Sartain, 1999. "Determinants of the Consumer Bankruptcy Decision,”The Journal of Finance, 51(1), 403-420.

[12] Edelberg, Wendy, 2003. "Risk-based Pricing of Interest Rates in Household Loan Markets,"Finance and Economics Discussion Series . Washington: Board of Governors of the Federal Reserve System 2003-62.

[13] Fay, Scott; Erik Hurst and Michelle J. White, 2002. "The Household Bankruptcy Decision,"American Economic Review, 92(3), 706-718.

[14] Gross, David B. and Nicholas S. Souleles, 2002. "An Empirical Analysis of Personal Bankruptcy and Delinquency,"The Review of Financial Studies, 15(1), 319-347. 
[15] Gross, David B. and Nicholas S. Souleles, 2002. "Do Liquidity Constraints and Interest Rates Matter for Consumer Behaviour? Evidence from Credit Card Data,'The Quarterly Journal of Economics, 117(1), 149185 .

[16] Huggett, Mark, 1993. "The risk-free rate in heterogeneous-agent incomplete-insurance economies,"Journal of Economic Dynamics and Control, 17(5-6), 953-969.

[17] Li, Wenli and Pierre-Daniel Sarte, 2003. "The macroeconomics of U.S. consumer bankruptcy choice: Chapter 7 or Chapter 13?"Federal Reserve Bank of Philadelphia, Working Paper 03-14.

[18] Livshits, Igor; James MacGee and Michele Tertilt, 2005. "Accounting for the Rise in Consumer Bankruptcies, "mimeo.

[19] Musto, David K. 2004. "What Happens When Information Leaves a Market? Evidence from Postbankruptcy Consumers, "Journal of Business, 77(4), 725-748.

[20] Padilla, A. Jorge and Marco Pagano. 2000. "Sharing default information as a borrower discipline device,"European Economic Review, 44(10), 1951-1980.

[21] Sullivan, Teresa A.; Elizabeth Warren and Jay Lawrence Westbrook. 2000. The Fragile Middle Class. Yale University PRess, New Haven and London. 


\section{Appendix}

Lemma 1 Agent's borrowing/payment at the credit limit, $b^{*}=b(T) \geq-\rho L$, satisfies:

$$
u^{\prime}\left(y^{I}+b^{*}\right) \leq \frac{\left[u\left(y^{I}+b^{*}\right)+\delta_{\theta} V^{P}(L ; \theta)\right]-\left[u\left(\theta y^{I}\right)+\delta_{\theta} V^{D}(\theta)\right]}{\rho L+b^{*}}
$$

with equality if $b^{*}>-\rho L$. Moreover, if (5) holds then (6) uniquely determines $b^{*}$.

Proof. If (5) does not hold, i.e. the agent does not find it optimal to default at the credit limit, then $b^{*}=-\rho L$ which satisfies (6). If (5) holds and the agent defaults at the limit, then (6) uniquely determines $b^{*}$. To see this point note that (6) can be rearranged as:

$$
u^{\prime}\left(y^{I}+b^{*}\right)\left(\rho L+b^{*}\right)-\left[u\left(y^{I}+b^{*}\right)+\delta_{\theta} V^{P}(L ; \theta)\right]+\left[u\left(\theta y^{I}\right)+\delta_{\theta} V^{D}(\theta)\right]=0 .
$$

If (6) holds, then left hand side of (19), which is decreasing in $b^{*}$ due to concavity of $u(\cdot)$, is positive for $b^{*}=-\rho L$. Moreover, since $u(\cdot)$ is strictly concave as $b^{*} \rightarrow \infty$, left hand side approaches $-\infty$. Then by continuity (6) has a unique solution.

The optimality of solution for (19) follows from using calculus of variation for borrowing amount $\mathbf{b}$ when $D=L-\epsilon$ for a very small $\epsilon$. Suppose the agent wants to maximize her utility for the next $\overline{\Delta t}$ periods, where $\overline{\Delta t}$ is small enough, after which she will for sure default. If the agent borrows a constant stream of $\mathbf{b}$ before reaching the credit limit, when she will default, then it approximately takes $\triangle t=\frac{L-D}{\rho D+\mathbf{b}}$ periods to reach the limit. So the agent will approximately receive utility

$$
\triangle t\left[u\left(y^{I}+b^{*}\right)+\delta_{\theta} V^{P}(L ; \theta)\right]+(\overline{\triangle t}-\triangle t)\left[u\left(\theta y^{I}\right)+\delta_{\theta} V^{D}(\theta)\right] .
$$

Taking first order condition with respect to $\mathbf{b}$ and then letting $\epsilon \rightarrow 0$, yields (19).

Lemma 3 For $L_{1}<L_{2}$, if the agent's solution for (1) finds it optimal to increase the debt level up to the limit then:

$$
b\left(L_{1} ;\left(L_{1}, \rho\right)\right)<b\left(L_{1} ;\left(L_{2}, \rho\right)\right) .
$$

Proof. If $b\left(L_{1} ;\left(L_{1}, \rho\right)\right)=-\rho L_{1}$, that is the agent does not default at the limit, then since the agent increases her debt level up to the limit we should have $b\left(L_{1} ;\left(L_{2}, \rho\right)\right)>-\rho L_{1}$.

If $b\left(L_{1} ;\left(L_{1}, \rho\right)\right)=-\rho L_{1}$, that is the agent defaults at credit limit $L_{1}$, then from (5) it follows that she also defaults at credit limit $L_{2}$, therefore $b\left(L_{1} ;\left(L_{1}, \rho\right)\right)$ and $b\left(L_{2} ;\left(L_{2}, \rho\right)\right)$ are both governed by (19). From (19) it follows that:

$$
\frac{d b^{*}}{d L}=\frac{-\rho u^{\prime}\left(y^{I}+b\right)+\delta_{\theta} V_{D}^{P}(D ; \theta)}{u^{\prime \prime}\left(y^{I}+b\right)(\rho D+b)} .
$$

Now comparing (20) and (12) it follows that

$$
\frac{d b^{*}}{d L}>\left.\frac{d b(D ;(L, \rho))}{d D}\right|_{D=L}
$$

hence by continuity of $b^{*}$ and $b(D ;(L, \rho)$ it follows

$$
b\left(L_{1} ;\left(L_{1}, \rho\right)\right)<b\left(L_{1} ;\left(L_{2}, \rho\right)\right) .
$$

Lemma 5 If $r=\beta$, then $V_{D}^{P}(D ; \theta)$ is decreasing in $D$ for $D \in\left[0, \frac{\underline{y}^{P}(1-\theta)}{r}\right]$ and increasing for $D>\frac{\underline{y}^{P}(1-\theta)}{r}$. 
Proof. For $D \in\left[0, \frac{\underline{y}^{P}(1-\theta)}{r}\right]$, concavity of $V^{P}(D ; \theta)$ follows from concavity of $u(\cdot)$ since the agent does not default after realizing her permanent income.

For $\frac{y^{P}(1-\theta)}{r} \leq D_{1}<D_{2}$ we have:

$$
\begin{aligned}
V_{D}^{P}\left(D_{2} ; \theta\right) & =-\int_{\frac{r D_{2}}{1-\theta}}^{\infty} u^{\prime}\left(y^{P}-r D_{2}\right) d F_{\theta}^{P}\left(y^{P}\right) \\
& =-\int_{\frac{r D_{2}}{1-\theta}-r\left(D_{2}-D_{1}\right)}^{\infty} u^{\prime}\left(y^{P}-r D_{1}\right) d F_{\theta}^{P}\left(y^{P}\right) \\
& >-\int_{\frac{r D_{1}}{1-\theta}}^{\infty} u^{\prime}\left(y^{P}-r D_{1}\right) d F_{\theta}^{P}\left(y^{P}\right) \\
& =V_{D}^{P}\left(D_{1} ;\left(y^{I}, \theta\right)\right)
\end{aligned}
$$

where the inequality follows from $D_{2}>D_{1}$ and $u^{\prime}(\cdot)>0$.

Lemma 6 For $r=\beta$, if $\left(\delta_{\theta}+\beta-\rho\right) u^{\prime}\left(y^{I}\right)+\delta_{\theta} V_{D}^{P}\left(\frac{\underline{y}^{P}(1-\theta)}{r} ; \theta\right)>0$ then the agent does not stop increasing her debt before getting to the credit limit.

Proof. The previous lemma guarantees that $\frac{\delta_{\theta}+\beta-\rho}{\delta_{\theta}} u^{\prime}\left(y^{I}\right)+V_{D}^{P}(D ; \theta)>0$ for $\forall D>0$.

Suppose the agent stops increasing her debt level above $\bar{D}$, that is $\rho \bar{D}+b(\bar{D})=0$, while $\bar{D}<L$. In this case the marginal benefit from increasing the borrowing amount is $\left(\delta_{\theta}+\beta\right) u^{\prime}\left(y^{I}+b(\bar{D})\right)$ and the marginal cost is $\rho u^{\prime}\left(y^{I}+b(\bar{D})\right)-\delta V_{D}^{P}(\bar{D} ; \theta)$. Concavity of $u(\cdot)$ guarantees $\left(\delta_{\theta}+\beta-\rho\right) u^{\prime}\left(y^{I}+b(\bar{D})\right)+\delta V_{D}^{P}(\bar{D} ; \theta)>0$ hence it is optimal to increase $b(\bar{D})$ and therefore the debt level.

Lemma 9 If the support of $\psi(\cdot \mid \tilde{\theta})$ is bounded away from zero, the utility function $u(\cdot)$ is unbounded from above and the expected present value of all future income for an agent with signal $\tilde{\theta}$ is bounded then:

$$
\lim _{L \rightarrow \infty} \Pi(\tilde{\theta} ;(L, \rho))<0 \forall \rho .
$$

Proof. First we show for any $\rho \geq r$ we have $\lim _{L \rightarrow \infty} V^{I}((L, \rho) ; \tilde{\theta}) \rightarrow \infty$. Next we show if $\Pi(\tilde{\theta} ;(L, \rho)) \geq 0$ then $V^{I}((L, \rho) ; \tilde{\theta})$ is bounded from above.

For any credit limit $L$, consider the plan of borrowing $b=\frac{\rho L}{e^{\rho}-1}$ during $t \in[0,1]$, and then defaulting. Also always defaulting after realizing the permanent income. This plan delivers the expected present value of utility equal to

$$
\iint \frac{1}{\delta_{\theta}+\beta}\left[\left(1-e^{-\left(\delta_{\theta}+\beta\right)}\right) u\left(y^{I}+\frac{\rho L}{e^{\rho}-1}\right)+e^{-\left(\delta_{\theta}+\beta\right)} u\left(\theta y^{I}\right)+\delta_{\theta} V^{D}(\theta)\right] d F_{\theta}^{I}\left(y^{I}\right) d \psi(\theta \mid \tilde{\theta})
$$

This is a lower bound for $V^{I}((L, \rho) ; \tilde{\theta})$, and If the support of $\psi(\cdot \mid \tilde{\theta})$ is bounded away from zero, this lower bound goes to infinity as $L \rightarrow \infty$, due to unboundedness of $u(\cdot)$. Hence $\left.V^{I}((L, \rho) ; \tilde{\theta})\right)$ is unbounded as $L \rightarrow \infty$.

Let's $\overline{y_{\tilde{\theta}}}$ denotes the stream of income which has the same present value as the expected present value of all future income for an agent with rating signal $\tilde{\theta}$ at interest rate $r$. That is

$$
\overline{y_{\tilde{\theta}}}=\iiint \frac{1}{r+\delta_{\theta}}\left(r y^{I}+\delta_{\theta} y^{P}\right) d F_{\theta}^{P}\left(y^{P}\right) d F_{\theta}^{I}\left(y^{I}\right) d \psi(\theta \mid \tilde{\theta}) .
$$

Due to the concavity of $u(\cdot)$, if $\Pi(\tilde{\theta} ;(L, \rho)) \geq 0$ then $V^{I}((L, \rho) ; \tilde{\theta}) \leq \frac{1}{\beta} u\left(\overline{y_{\tilde{\theta}}}\right)$. Since $V^{I}((L, \rho) ; \tilde{\theta})$ is bounded from above when $\Pi(\tilde{\theta} ;(L, \rho)) \geq 0$ and is unbounded when $L \rightarrow \infty$, we conclude $\lim _{L \rightarrow \infty} \Pi(\tilde{\theta} ;(L, \rho))<0$ 
Theorem 10 If the support of $\psi(\cdot \mid \tilde{\theta})$ is bounded away from zero, the utility function $u(\cdot)$ is unbounded from above and the expected present value of all future income for an agent with signal $\tilde{\theta}$ is bounded then creditors' problem (17) has solution.

Proof. By definition, for a given interest rate $\rho$, agent's expected utility $\Pi(\tilde{\theta} ;(L, \rho))$ is increasing, as agents can opt out and do not use credit limit. Let's $L^{*}(\tilde{\theta} ; \rho)$ denotes the largest $L$ such that $\Pi(\tilde{\theta} ;(L, \rho))=0$. Since $\Pi(\tilde{\theta} ;(0, \rho))=0$ and $\Pi(\tilde{\theta} ;(L, \rho))$ is continuous in $L$, the previous lemma guarantees the existence and uniqueness of $L^{*}(\tilde{\theta} ; \rho)$. Creditors' problem (17) can be rewritten as:

$$
\max _{\rho} V^{I}\left(\left(L^{*}(\tilde{\theta} ; \rho), \rho\right) ; \tilde{\theta}\right)
$$

Notice that $V^{I}\left(\left(L^{*}(\tilde{\theta} ; \rho), \rho\right) ; \tilde{\theta}\right)$ is continuous in $\rho$.

Following the proof of the previous lemma we know $V^{I}\left(\left(L^{*}(\tilde{\theta} ; \rho), \rho\right) ; \tilde{\theta}\right) \leq \frac{1}{\beta} u\left(\overline{y_{\tilde{\theta}}}\right)$ for $\forall \rho$. Since the support of $y^{I}$ and $y^{P}$ are uniformly bounded away from zero, the support of $\psi(\cdot \mid \tilde{\theta})$ is bounded away from zero and $\overline{y_{\tilde{\theta}}}$ is finite, $\exists \bar{\rho}$ such that for $\rho>\bar{\rho}$ no agent increases her debt level above zero if she is offered a contract with interest rate $\rho$, that is

$$
\left.V^{I}\left(\left(L^{*}(\tilde{\theta} ; \rho), \rho\right) ; \tilde{\theta}\right)=V^{I}(0, r) ; \tilde{\theta}\right) \quad \forall \rho>\bar{\rho} .
$$

The bounded continuous function $V^{I}\left(\left(L^{*}(\tilde{\theta} ; \rho), \rho\right) ; \tilde{\theta}\right)$ attains its maximum on a compact set. 